\title{
Examining the complexity of wellbeing profiles in a large cross-national community sample
}

\author{
Richard Burns · Dimity Crisp
}

\begin{abstract}
The existence of multiple wellbeing indicators reflecting Psychological, Subjective and Social Wellbeing domains is widely reported. However, there is limited examination of the wellbeing profiles individuals report across multiple indicators. The current paper utilises a latent profile framework to examine the extent individuals report different wellbeing profiles. Participants $(n=42,038)$ were from the European Social Survey (ESS), a large multinational study who completed the ESS wellbeing module. Profiles analyses identified no complexity in the experiences of groups of individuals across different wellbeing indicators; individuals who scored high (or low) on one indicator scored high (or low) on the other indicators. Similarly, analysis of higher-order wellbeing dimensions were consistent, no complexity was reported. Different profile classes simply reflected groups of individuals who generally scored at consistent levels across multiple wellbeing indicators.
\end{abstract}

Keywords: latent class analysis; mixture analysis; profile analysis; psychological wellbeing; subjective wellbeing; social wellbeing.

\section{Introduction}

Wellbeing is a fundamental issue for quality of life research (Benyamini et al., 2000; Boehm \& Kubzansky, 2012; Veenhoven, 1995). Wellbeing is frequently described in terms of multiple wellbeing indicators that are usually ascribed to one of two theoretical frameworks, Psychological (PWB) and Subjective (SWB) Wellbeing (Deci \& Ryan, 2000; Huppert et al., 2009; Keyes et al., 2002). While PWB is reflected by eudaimonic indicators of personal functioning (e.g. purpose in life, mastery), SWB emphasises hedonic indicators of personal feeling (e.g. positive and negative mood) and appraisal (e.g. life satisfaction). A multi-dimensional wellbeing structure with two higher-order factors reflecting PWB and SWB is frequently described in the literature (Burns \& Machin, 2009; Compton et al., 1996; Hervás \& Vázquez, 2013; Linley et al., 2009). In addition, extensions to a two factor hierarchical structure have emphasised a third dimension reflecting social and inter-personal wellbeing (SoWB) (Gallagher et al., 2009; Huppert et al., 2009; Keyes, 1998).

There has been debate however whether a correlated or hierarchical factor structure is the best theoretical model for describing the relationship between multiple wellbeing domains. While many researchers may emphasise better comparative fit of a correlated factor structure, models that utilise a superordinate higher-order factor reflected by lower-order SWB, PWB and SoWB factors, often report acceptable and comparable fit (Gallagher et al., 2009; Ryff \& Keyes, 1995). And there are a number of studies that have identified models which incorporate a superordinate higher-order factor structure as better fitting than models with correlated wellbeing 
factors only (Burns, 2020; Hervás \& Vázquez, 2013; Kim et al., 2016; Van Horn et al., 2004). Increasingly, analyses within a bi-factor modelling framework, tend to support an argument that multiple wellbeing indicators may generally reflect by a general wellbeing factor (Chen et al., 2013; de Bruin \& du Plessis, 2015; Gatt et al., 2014; Hides et al., 2016; Jovanović, 2015; Longo et al., 2020). It is important to emphasise that the existence of a higher-order or general factor structure does not negate the importance of delineating between multiple indicators that tap different wellbeing dimensions. An argument has been made that distinctions between wellbeing frameworks belies the interconnectedness between hedonic and eudaimonic dimensions (Goodman et al., 2017) while Disabato et al. (2016) have identified correlations in the magnitude of 0.91 and 0.99 between SWB and PWB factors in their large cross-cultural study of over 7600 individuals. Relatedly, in their description of the development of the WB-Pro scale, Marsh et al. (2020) emphasised that 15 lower-level wellbeing domains reflected an overall global wellbeing measure and that many common wellbeing measures fail to capture the breadth of wellbeing domains, emphasising the importance of capturing multiple manifest indicators to reflect an underlying general 'wellbeing' factor.

\subsection{Profiles of wellbeing complexity}

The ubiquity of measuring multiple wellbeing dimensions is posited by many well-being researchers (Burns, 2020; Chen et al., 2013; de Bruin \& du Plessis, 2015; Gatt et al., 2014; Hervás \& Vázquez, 2013; Hides et al., 2016; Jovanović, 2015; Kim et al., 2016; Longo et al., 2020; Marsh et al., 2020; Van Horn et al., 2004), but another theoretical approach to examining the structure of wellbeing remains to be fully explored. That is, instead of analysing the relationship between wellbeing variables within and between higher-level domains, a profile analysis framework would focus on the ways in which different wellbeing components are concurrently experienced by individuals. Such an approach suggests a more complex set of inter-relationships between wellbeing components. Simply, instead of a variable-focused approach in which analysis focuses on individuals' scores on multiple variables or derived higher-order factors, the focus is on the inter-relationship between multiple variables. This approach is often described as person-centred as the focus is on individuals' pattern of responses across multiple indicators and implies a complexity of unique individual-level wellbeing profiles which differs between other individuals who may prioritise different wellbeing indicators.

There exists a substantial literature (Brose et al., 2015; Grühn et al., 2013; Kashdan et al., 2015; O'Toole et al., 2020) that has focused specifically on emotional or affective complexity, which focuses on the differentiation, covariation and variation of discrete emotions experienced simultaneously (emotional dialecticism) or the variety of emotions experienced (emotional differentiation). It is suggested that increased emotional complexity is adaptive and related to increased emotion-regulation (Hay \& Diehl, 2011) with improved mental and health outcomes (Hershfield et al., 2013; Ong \& Bergeman, 2004). But to date there have only been limited attempts to describe wellbeing complexity that focus on the complex distributions or unique individual profiles across levels of multiple SWB, PWB and SoWB indicators. Unfortunately, some of the methods that have been employed were methodologically naïve. For example, by categorising participants into tertile groups based on the distribution of participants on separate wellbeing dimensions, that is, by grouping individuals into levels of low, medium and high on each domain, Keyes et al. (2002) was able to compare the extent to which individuals reported comparable or disparate levels of PWB and SWB wellbeing. Participants who reported comparable levels of PWB and SWB were defined as 'on-diagonal' types (comparable levels of both PWB and SWB; e.g. high on both), while combinations of disparate PWB and SWB levels 
were defined as the 'off-diagonal' type (mixed levels of PWB and SWB; e.g. high on one, low on the other). Keyes et al. (2002) identified that $18.6 \%$ of a sample randomly drawn from the general population had optimal well-being, in that they scored high on both PWB and SWB, while 12.6\% and $19.3 \%$ reported moderate and low levels on both modes of well-being, respectively. Consequently, just under half of Keyes' sample (45.2\%) reported disparate combinations of wellbeing, with around $7 \%$ reporting the most extreme cross-diagonal types. That is, $4.2 \%$ reported high levels of PWB and low levels of SWB, and 3.1\% reported high levels SWB and low levels of PWB (Keyes et al., 2002). Other naïve methods have included using median splits to categories individuals into high or low wellbeing and distress (Savoie et al., 2010). Such approaches examine a more complex set of relationship between the wellbeing factors and allows for more careful consideration of the drivers of wellbeing outcomes. For instance, Neuroticism was the strongest predictor in determining the on-diagonal well-being types (e.g. high levels of both SWB and PWB) while Extraversion and Conscientiousness differentiated between individuals who scored consistently high or low on both SWB and PWB (Keyes et al., 2002). In terms of the more complex off-diagonal types, Keyes et al. (2002) identified that it was Openness to Experience which most differentiated between those who reported high levels of PWB and low levels of SWB from those individuals who reported low levels of PWB and high levels of SWB.

While informative, there are however limitations with approaches espoused by Keyes et al. (2002) and Savoie et al. (2010). Intuitively appealing, deriving groups based on a sample's distribution, either through the use median splits or based on tertile or quartile distributions, is biased and can lead to erroneous conclusions, depending on the underlying distribution of the variables within sample from which they are drawn (Altman, 1991; Bennette \& Vickers, 2012; Greenland, 1995; van Walraven \& Hart, 2008). Such naïve methods are not to be recommended, particularly when there are more robust and methodologically sound approaches to identifying subsets of individuals who can be classified according to their complex profiles on a set of manifest indicators.

More sophisticated profile analysis approaches have included the use of latent profile or mixture modelling methods (Lubke \& Miller, 2015; Muthén, 2004) which have been widely used in other fields (Lu et al., 2009). In clinical contexts, these approaches have been used to identify distinct methamphetamine psychosis-symptom profiles which are distinct from other psychosis profiles as found in schizophrenia (Bousman et al., 2015; McKetin et al., 2016), to identify different treatment-related trajectories of depression severity (Uher et al., 2010) and nicotine dependence (Hu et al., 2008), and in determining mental health classification structures (Lubke \& Miller, 2015; Muthen, 2006).

Unfortunately, there are very few examples of latent class or mixture profile methods to assess the existence of complex wellbeing profiles (Bhullar et al., 2014; Goodman et al., 2017; Morin et al., 2016). One example (Bhullar et al., 2014) applied a latent profile analysis method to derive different wellbeing profiles in a small sample of Australian University students on the Ryff PWB scales (Ryff, 1989). Results indicated that there were no complex mixture patterns between the PWB scales. Instead, the Bhullar et al. (2014) findings identified 5 separate homogenous groups that reflected on-diagonal types only. That is, participants who scored low on one PWB indicator scored lower on the other PWB indicators. Consequently, although different profiles were identified, the classes would essentially correspond to different levels of an overall PWB factor score. Similarly, analyses of the satisfaction with life and Seligman's (2011) PERMA model comprising positive emotions, engagement, relationships, meaning, and accomplishment, similarly reported on-diagonal wellbeing profiles (Goodman et al., 2017). Morin et al. (2016) identified classes based on a bi-factor analysis of measures of serenity, harmony, 
involvement, anxiety and depression; while informative in terms of its methodological contributions whereby profile analyses were undertaken on the bi-factors, differences between the classes were of very small effects $(<0.5 S D)$.

These contributions raise a number of questions; is the forcing of continuous random variables into discrete categorical groups such as exemplified by Keyes et al. (2002) in order to more easily create on and off-diagonal classifications an appropriate method? Or can more quantifiable methods capture the complex wellbeing profile relationships Keyes et al. (2002) identified. Even if such methods are to be preferred, given Bhullar et al. (2014) findings, might the overwhelmingly normative experience for most be that that wellbeing profiles are ondiagonal in nature? That is, there is little within-person variation across wellbeing indicators. Simply, individuals who score highest on one indicator will comparatively score highest on another indicator. This may give further support for the increasing ubiquity of a general wellbeing factor described in bi-factor and hierarchical models (Burns, 2020; Chen et al., 2013; de Bruin \& du Plessis, 2015; Gallagher et al., 2009; Gatt et al., 2014; Hervás \& Vázquez, 2013; Hides et al., 2016; Jovanović, 2015; Kim et al., 2016; Longo et al., 2020; Van Horn et al., 2004).

\subsection{The current study}

The aim of the current paper therefore is to examine wellbeing complexity in a very large community survey, and discriminate the ways in which participants report differently across different wellbeing components concurrently. As an extension of Bhullar et al. (2014) and Goodman et al. (2017) who focused on fewer wellbeing indicators, analysis identified the extent to which homogenous groups of individuals report different profiles across multiple PWB, SWB and SoWB components. That is, to what extent do different individuals prioritise some wellbeing indicators over other indicators, in which case scoring high on those which are of most value to them, and lower on those indicators which are of least important to them? These would reflect the off-diagonal typology reported by Keyes et al. (2002). Alternatively, consistent with Bhullar et al. (2014) findings, it may well be that many participants are consistent in the level of wellbeing they report across all indicators. Some participants may simply report high, medium or low across all indicators, reflecting the on-diagonal wellbeing typology. We consider analysis on the individual wellbeing indicators and subsequently on the higher-order SWB, PWB and SoWB factors. Finally, we consider the utility of the derived wellbeing classes, derived from both the individual level indicators and higher-order factors, by identifying differences in the sociodemographic characteristics of those ascribed to different classes, and the differential risk across a broad range of health, employment and economic outcomes. Sex and age differences in wellbeing and mental health are well established; typically older adults and males report better mental health (Burns et al., 2020; Charles et al., 2001; Ryff \& Singer, 2008; Shmotkin, 1990; Windsor et al., 2013) although age-related differences may be moderated by which wellbeing dimensions are most important (Bowling, 2010; Burns, 2020; Charles et al., 2001). Also, higher education is associated with better wellbeing and mental health outcomes (Araya et al., 2003; Fergusson \& Woodward, 2002). It will be important to confirm whether differences between profiles are similarly reported.

\section{Method}

\subsection{Participants}

Participant data from the European Social Survey (ESS) were obtained from the online ESS website (www.europeansocialsurvey.org). The ESS is a large international survey of European 
social attitudes and has been funded by the European Commission, and the European Science and National Science Foundations. Background and detail about the ESS have been described previously (Jowell, 2007). Data for the current paper was from the third wave of data collection (European Social Survey, 2006). Participants in this study $(n=42,999)$ were from 23 countries that included Austria, Belgium, Bulgaria, Switzerland, Cyprus, Germany, Denmark, Estonia, Spain, Finland, France, Great Britain, Hungary, Ireland, Netherlands, Norway, Poland, Portugal, Russia, Sweden, Slovenia, Slovakia and Ukraine. Participants were on average 47.7 years of age $(S D=18.6$ years; range $=14-101) ; 54.4 \%$ were female and provided self-reported wellbeing data.

\subsection{Measures}

\subsubsection{Wellbeing outcomes}

Wellbeing was measured with the ESS Wellbeing Module which has previously been fully described elsewhere (Burns, 2020; Huppert et al., 2009; Huppert \& So, 2013). The ESS module comprises a multi-dimensional wellbeing scale that includes items that capture multiple dimensions of personal feeling and functioning and intra-personal social dimensions. Specifically, the feeling or SWB component was assessed in terms of Positive and Negative Emotions, Vitality, Self-Esteem, Satisfaction, the functional or PWB component in terms of Competence, Autonomy, Engagement, Resilience, and Purpose and social wellbeing or SoWB component in terms of Social Support, Social Trust and Belongingness. SWB was assessed with items that captured Positive Emotion (e.g. "How much of the time during the past week have you enjoyed life"), Negative Emotions (e.g. "How much of the time during the past week have you felt sad"), Vitality (e.g. "How much of the time during the past week have you had a lot of energy?"), Self-Esteem (e.g. "In general I feel very positive about myself"), Satisfaction (e.g. "All things considered, how satisfied are you with life as a whole nowadays?") and Optimism (e.g. "I am always optimistic about my future"). PWB was captured by items reflecting Competence (e.g. "Most days I feel a sense of accomplishment from what I do"), Autonomy (e.g. "I feel I am free to decide how to live my life"; $\alpha=.79$ ), Engagement (e.g. "How much of the time during the past week have you been absorbed in what you were doing"), Purpose (e.g. "I generally feel that what I do in my life is valuable and worthwhile"), and Resilience (e.g. "When things go wrong in my life it takes a long time to get back to normal"). The SoWB dimensions were defined by items reflecting Social Support (e.g. "There are people in my life who really care about me"), Social Trust and Belongingness (e.g. "To what extent do you feel that people in your local area help one another?"). Wellbeing scores for each wellbeing dimension were computed from factor analysis and Z-Standardized $(\mathrm{M}=0 ; \mathrm{SD}=1)$.

\subsubsection{Socio-demographic and health variables}

Derived classes of wellbeing were compared against a range of socio-demographic characteristics including Sex (Female vs. Male), Partner Status (Partnered vs. Not Partnered), Education (Tertiary Education vs. No Tertiary Education), and chronological age (in years). Health was assessed with a measure of sleep quality ("How much your sleep was restless the last week") scored on a scale of "None or almost none of the time", "Some of the time", "Most of the time", and "All of almost all of the time". Employment outcomes were measured in terms of an individual's employment status (Employed vs. Unemployed) and their partner's employment status (Employed vs. Unemployed). Economic health was assessed with an item of financial distress (No difficulty living on present income vs. Difficulty living on present income). The socio-demographic characteristics of the analytical sample are provided in Table 1 (below). 
Table 1. Socio-demographic characteristics of the analysis sample

\begin{tabular}{lccc}
\hline & Total Sample & Male & Female \\
\cline { 2 - 4 } Male & $\mathrm{N}(\%)$ & $\mathrm{N}(\%)$ & $\mathrm{N}(\%)$ \\
\cline { 2 - 4 } Age, M(SD) & $18,989(45.7)$ & - & - \\
Sleep Quality, M(SD) & $47.42(18.39)$ & $46.45(18.16)$ & $48.23(18.54)$ \\
Partnered & $1.80(.85)$ & $1.69(.80)$ & $1.90(.88)$ \\
Tertiary Education & $22,203(53.7)$ & $8,162(43.3)$ & $10,941(48.9)$ \\
Unemployed (Self) & $11,339(27.4)$ & $5,137(27.2)$ & $6,179(27.5)$ \\
Unemployed (Partner) & $2,174(5.2)$ & $1,017(5.4)$ & $1,154(5.1)$ \\
Difficulty Living on Household Income & $1,003(2.4)$ & $546(2.9)$ & $455(2.0)$ \\
\hline
\end{tabular}

\subsection{Statistical analyses}

Latent Profile Analysis (LPA) was used to identify homogenous groups of participants who differ from other groups based on the within-class relationships across the different wellbeing indicators. Similar to Latent Class Analysis (LCA), LPA extends LCA approaches by using continuous indicators to estimate conditional means and variances of the continuous indicators. There is an assumption in LPA of conditional independence. That is, the covariance between all observed indicators are constrained to zero as any correlation between the observed indicators should be reflected by the latent profile. Also, LPA imparts equality constraints on the variances of the continuous indicators between the derived classes. Both the covariance and variance assumptions can be relaxed and there is no clear explanation in the literature regarding the missspecification of these parameters (Lubke \& Miller, 2015; Muthen, 2008; Nylund-Gibson \& Choi, in press). Therefore, the LPA were undertaken under the assumption of conditional independence and with equality constraints on the variances of the continuous indicators.

Multiple profile analyses increasingly derived additional classes of individuals that reflect homogenous profile classes across the multiple wellbeing indicators. Determining the correct number of classes to derive was based on a combination of model fit indices and model parsimony. The best-fitting models were assessed using several GFI including the BIC, Entropy - reflecting the proportion of cases correctly classified into their respective class, the adjusted LoMendell-Rubin (LMR) Likelihood Ratio Test and the Vuong-Lo-Mendell-Rubin (VLMR) Likelihood Ratio Test (Lo et al., 2001; Nylund et al., 2008). The profile analyses were undertaken in MPlus v7. Participants who provided at least 1 response were all included in the analyses; 767 participants $(1.7 \%$ of the total sample) reported missing on any item but available data was retained with a maximum likelihood estimation method.

\section{Results}

\subsection{Latent profile analysis of individual wellbeing indicators}

Comparison of the goodness of fit indices between a series of models that incrementally increased the number of classes to be derived revealed improving model fit for up to 11 classes in terms of the AIC and BIC statistics where smaller values reflect better fit (Table 2; below). However, entropy does drop from .89 to .85 from the 2 to 3 model classes, but otherwise stabilises at .80 to .82 from the 4 -class model. Two Likelihood Ratio tests supported increasing the number of classes derived up to and including a model with 9 classes. Model parsimony raises question of the need for additional classes that include only very small proportions of respondents. In the 9-class model, 4 classes reported proportions of $<5 \%$ (Class $1=4.6 \%$; Class $2=1.2 \%$; Class $3=3.0 \%$; Class 
$4=2.3 \%$ ). In the 6-, 7- and 8-class model, 2 classes reported proportions of $<5 \%$ (6 Class Model: Class $1=2.8 \%$; Class $4=3.7 \%$; 7 Class model: Class $1=2.2 \%$; Class $2=4.2 \% ; 8$ Class Model: Class $1=2.4 \%$; Class $6=3.7 \%$ ). And in the 5-class model, 1 class (Class 1 ) reported proportions of $<$ $2.3 \%$. All classes in the 4-class model reported proportions $>5.0 \%$. These classes with low proportions differentiated participants who scored low across all wellbeing variables; that is, at least $0.5 \mathrm{SD}$ below the mean across all wellbeing indicators. For model simplicity, they are captured by the two low wellbeing groups in the 4-class model (see Figure 1). In addition, and as a comparison, plots for models with up to 6 classes are displayed in Figures $2 \mathrm{a}$ thru $2 \mathrm{~d}$, to demonstrate that across models, classes reflect stability of scores across wellbeing measures. The only complexity was reported by Class 4 participants in the 6-class model, but who only reflect $3.7 \%$ of the sample; they still reported below average across wellbeing indicators. This class was consistent in the additional 7-, 8- and 9-class models but was not retained owing to the very small proportions captured in the class and based on the consistently low scores reported by the class.

Table 2. Comparison of goodness of fit indices for models with increasing number of classes

\begin{tabular}{cccccccr}
\hline Class & AIC & BIC & Entropy & $\begin{array}{c}\text { VLMR- } \\
\text { LRT }\end{array}$ & P & LMR-LRT & P \\
\hline 2 & 1459028 & 1459247 & .89 & 120152.7 & .333 & 119353.6 & .333 \\
3 & 1424274 & 1424571 & .85 & 34782.0 & $<.001$ & 34550.6 & $<.001$ \\
4 & 1410658 & 1411032 & .81 & 13644.0 & $<.001$ & 13553.2 & $<.001$ \\
5 & 1405435 & 1405885 & .80 & 5251.2 & $<.001$ & 5216.3 & $<.001$ \\
6 & 1400209 & 1400736 & .81 & 5253.7 & $<.001$ & 5218.8 & $<.001$ \\
7 & 1396651 & 1397255 & .80 & 3586.3 & $<.001$ & 3562.4 & $<.001$ \\
8 & 1393142 & 1393823 & .80 & 3536.6 & $<.001$ & 3513.1 & $<.001$ \\
9 & 1390204 & 1390962 & .81 & 2966.2 & $<.001$ & 2946.5 & $<.001$ \\
10 & 1387847 & 1388682 & .81 & 2384.8 & .458 & 2368.9 & .460 \\
11 & 1385812 & 1386724 & .82 & 2063.8 & .179 & 2050.0 & .180 \\
\hline
\end{tabular}

Note. AIC: Akaike Information Criteria; BIC: Bayesian Information Criteria; VLMR LRT: Vuong-LoMendell-Rubin Likelihood Ratio Test; LMR LRT: Lo-Mendell-Rubin Likelihood Ratio Test

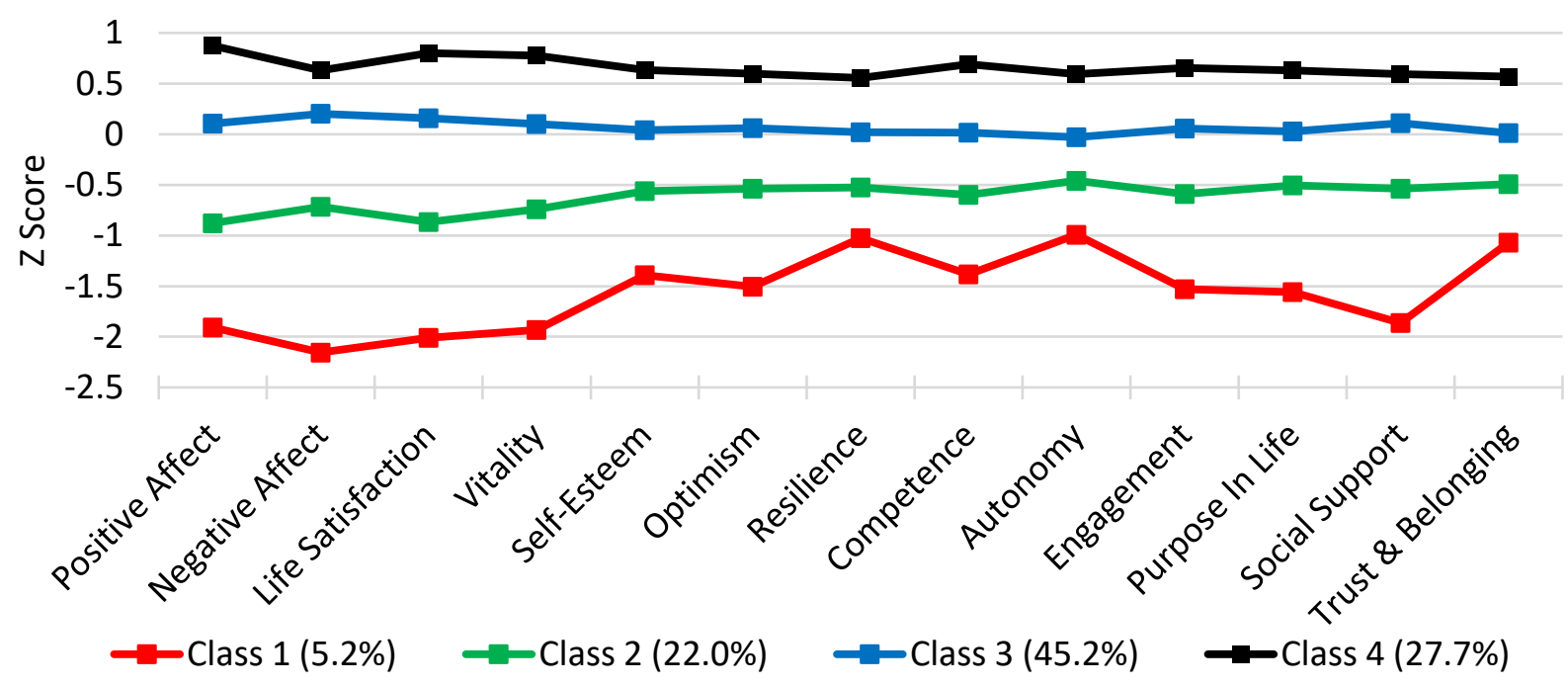

Figure 1. A 4-class profile analysis of wellbeing indicators

Note. Negative Affect has been reversed scored so a high score reflects better outcomes (e.g. lower negative affect). 


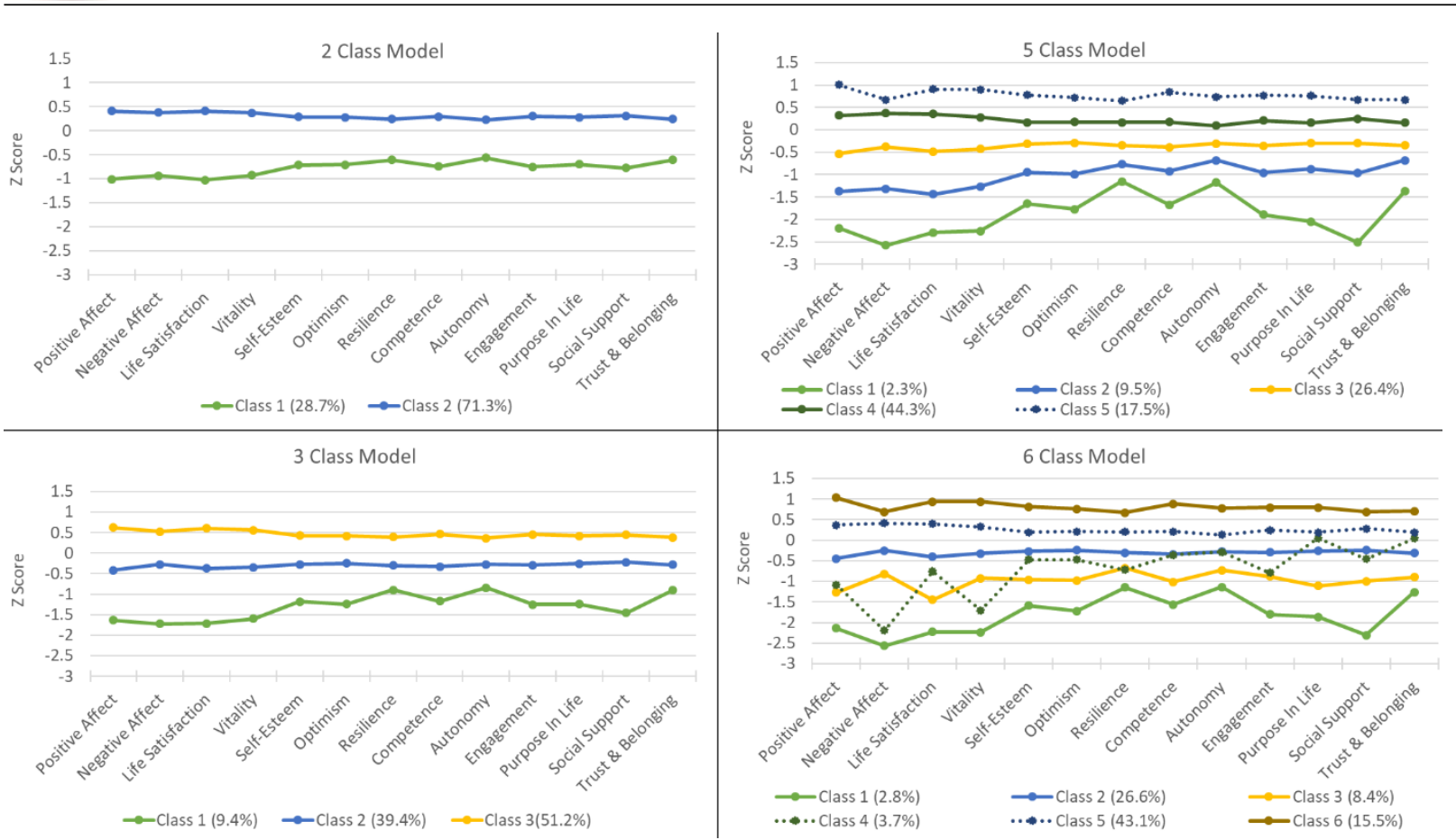

Figure 2a-2d. Display of 2 thru 6-class profile analysis of wellbeing and mental health Note. Negative Affect has been reversed scored so a high score reflects better outcomes (e.g. lower negative affect).

The classification probabilities for most likely latent class membership, based on the posterior probabilities, were high; $94.4 \%(\mathrm{SE}=0.2)$ for Class 1, 90.7\% $(\mathrm{SE}=0.1)$ for Class $2,87.3 \%(\mathrm{SE}=0.1)$ for Class 3, and $88.1 \%(\mathrm{SE}=0.1$ ) for Class 4 (See Table 3). Where observations were not assigned their correct class based on the posterior probabilities, they were assigned to a class adjacent to their class. That is, $5.6 \%$ of the participants in Class 1 (the lowest wellbeing class) were not correctly assigned Class 1 membership based on the posterior probabilities, but were assigned into the adjacent Class 2 (the second lowest level of wellbeing). None of the observations from Class 1 were assigned any probability for being in the 2 highest classes. At the other end of the spectrum, those observations (11.9\%) assigned Class 4 membership (the highest wellbeing class) but not correctly identified as Class 4 members from the posterior probabilities, were assigned membership of Class 3 (the second highest wellbeing class). For the middle classes (Classes 2 and 3 ), observations were mostly correctly assigned into their correct class, or the adjacent class (i.e. Class 1 or 3 for members of Class 2; Cass 2 or 4 for members of Class 3). Hence we can conclude that most were correctly assigned their class based on posterior probabilities, but if members were not correctly assigned their most likely class, they were assigned into an adjacent class.

Table 3. Average class probabilities of posterior

\begin{tabular}{|c|c|c|c|c|}
\hline \multirow{3}{*}{ Class Membership } & \multicolumn{4}{|c|}{ Class Membership based on Posterior Probabilities } \\
\hline & 1 & 2 & 3 & 4 \\
\hline & $\mathrm{M}(\mathrm{SE})$ & $\mathrm{M}(\mathrm{SE})$ & $\mathrm{M}(\mathrm{SE})$ & $\mathrm{M}(\mathrm{SE})$ \\
\hline 1 & $94.4(0.2)$ & $5.6(0.2)$ & $0(0)$ & $0(0)$ \\
\hline 2 & $1.6(0.1)$ & $90.7(0.1)$ & $7.7(0.1)$ & $0(0)$ \\
\hline 3 & $0(0)$ & $4.5(0.1)$ & $87.3(0.1)$ & $8.2(0.1)$ \\
\hline 4 & $0(0)$ & $0(0)$ & $11.9(0.1)$ & $88.1(0.1)$ \\
\hline
\end{tabular}


Comparison of the mean class estimates on the overall wellbeing and individual wellbeing indicators as well as key socio-demographic characteristics are reported in Table 4. Across all of the individual wellbeing dimensions, the lowest scores were reported by participants in Class 1 with consistent increases in wellbeing associated with increased Class number; that is, those in Class 4 reported the highest wellbeing scores across all wellbeing indicators. Importantly, the comparison on an overall higher-order wellbeing factor score again showed that those in Class 1 reported the lowest overall wellbeing score, with scores increasing for the other classes. Sociodemographic differences between classes are also reported. Generally, those who reported average and higher levels of wellbeing, those participants assigned to Classes 3 and 4, were of younger age and more likely to be partnered; there appears to be a gradient increase in wellbeing class and partnered status. There appears to be greater proportion of females and those with no tertiary education in the lower wellbeing classes (Classes 1 and 2). That no complex relationships were identified between wellbeing indicators is noteworthy. Indeed, examination of the correlation between the individual indicators generally show relationships of a moderate to high magnitude $(\mathrm{r}=0.42-\mathrm{r}=.0 .81)$ between the multiple individual wellbeing indicators and the overall wellbeing scale, suggesting a substantial degree of rank-order stability between individuals (Table 5; below).

Table 4. Socio-demographic and wellbeing characteristics of class membership

\begin{tabular}{|c|c|c|c|c|c|}
\hline & \multicolumn{4}{|l|}{ Class } & \multirow[t]{3}{*}{ Test Statistic } \\
\hline & 1 & 2 & 3 & 4 & \\
\hline & $\mathrm{M}(\mathrm{SE})$ & $\mathrm{M}(\mathrm{SE})$ & $\mathrm{M}(\mathrm{SE})$ & $\mathrm{M}(\mathrm{SE})$ & \\
\hline \multicolumn{6}{|l|}{ Wellbeing } \\
\hline Overall Wellbeing & $-1.13(.03)$ & $-.52(.01)$ & $.03(.00)$ & $.57(.01)$ & $\mathrm{F}(3)=4461.89 ; \mathrm{p}<.001$ \\
\hline Positive Emotions & $-.96(.03)$ & $-.50(.01)$ & $.03(.01)$ & $.52(.01)$ & $\mathrm{F}(3)=2981.02 ; \mathrm{p}<.001$ \\
\hline Negative Emotions & $-1.05(.03)$ & $-.41(.01)$ & $.10(.01)$ & $.36(.01)$ & $\mathrm{F}(3)=2153.56 ; \mathrm{p}<.001$ \\
\hline Life Satisfaction & $-.97(.03)$ & $-.47(.01)$ & $.07(.01)$ & $.44(.01)$ & $\mathrm{F}(3)=2161.84 ; \mathrm{p}<.001$ \\
\hline Vitality & $-.92(.03)$ & $-.41(.01)$ & $.03(.01)$ & $.45(.01)$ & $\mathrm{F}(3)=2213.06 ; \mathrm{p}<.001$ \\
\hline Self-Esteem & $-.72(.03)$ & $-.33(.01)$ & $.00(.01)$ & $.39(.01)$ & $\mathrm{F}(3)=1441.96 ; \mathrm{p}<.001$ \\
\hline Optimism & $-.72(.03)$ & $-.32(.01)$ & $.01(.01)$ & $.37(.01)$ & $\mathrm{F}(3)=1204.69 ; \mathrm{p}<.001$ \\
\hline Resilience & $-.49(.02)$ & $-.30(.01)$ & $-.00(.01)$ & $.33(.01)$ & $\mathrm{F}(3)=905.67 ; \mathrm{p}<.001$ \\
\hline Competence & $-.69(.03)$ & $-.34(.01)$ & $-.01(.01)$ & $.41(.01)$ & $\mathrm{F}(3)=1508.18 ; \mathrm{p}<.001$ \\
\hline Autonomy & $-.51(.03)$ & $-.27(.01)$ & $-.03(.01)$ & $.37(.01)$ & $\mathrm{F}(3)=997.89 ; \mathrm{p}<.001$ \\
\hline Engagement & $-.74(.03)$ & $-.31(.01)$ & $.01(.01)$ & $.38(.01)$ & $\mathrm{F}(3)=1389.11 ; \mathrm{p}<.001$ \\
\hline Purpose In Life & $-.75(.03)$ & $-.28(.01)$ & $-.01(.01)$ & $.38(.01)$ & $\mathrm{F}(3)=1313.95 ; \mathrm{p}<.001$ \\
\hline Social Support & $-.90(.03)$ & $-.30(.01)$ & $.03(.01)$ & $.35(.01)$ & $\mathrm{F}(3)=1497.06 ; \mathrm{p}<.001$ \\
\hline Trust and Belonging & $-.58(.03)$ & $-.28(.01)$ & $-.01(.01)$ & $.35(.01)$ & $\mathrm{F}(3)=1008.98 ; \mathrm{p}<.001$ \\
\hline \multicolumn{6}{|l|}{ Socio-Demographic } \\
\hline Age & $51.24(.40)$ & $49.05(.19)$ & $46.93(.13)$ & $47.23(.17)$ & $F(3)=56.48 ; p<.001$ \\
\hline Not Partnered, N(\%) & 1, $203(55.5)$ & $4,557(49.3)$ & $9,155(46.5)$ & $4,970(42.9)$ & $\chi^{2}(3)=161.82 ; p<.001$ \\
\hline Female Sex, N(\%) & 1, $294(59.5)$ & $5,353(57.7)$ & $10,700(54.1)$ & $6,026(51.7)$ & $\chi^{2}(3)=97.63 ; p<.001$ \\
\hline Tertiary Educated, $\mathrm{N}(\%)$ & $447(20.6)$ & $2,204(23.8)$ & $5,317(26.9)$ & $3,640(31.3)$ & $\chi^{2}(3)=203.29 ; p<.001$ \\
\hline
\end{tabular}

Note. The $\mathrm{F}$ test is from a one-way ANOVA; all pairwise comparisons were statistically significant $\mathrm{p}<.001$ except age differences between Class 4 and $3(p=.495) ; \chi^{2}$ is from a chi-square test.

\subsection{Latent profile analysis of higher-order wellbeing domains}

We re-estimated our mixture models to identify potential wellbeing complexity on the higherorder factors reflecting SWB, PWB and SoWB. As with our analysis of the individual indicators, we ran a series of models that incrementally increased the number of mixture classes based on participants' scores on SWB, PWB and SoWB. Comparison of the model fit between a series of models that incrementally increased the number of classes to be derived revealed improving 
model fit for up to 12 classes in terms of the AIC and BIC statistics where smaller is better (Table 6). However, entropy does drop from .80 and .77 from the 2 to 3 class models, but otherwise stabilises at .70 to .73 from the 4 class model. Two Likelihood Ratio tests supported increasing the number of classes derived up to and including a model with 7 classes.

Table 5. Correlations between wellbeing indicators

\begin{tabular}{|c|c|c|c|c|c|c|c|c|c|c|c|c|c|c|c|}
\hline & WB & Auto & Comp & Engag & Purp & Supp & Belon & Resil & PA & NA & Happ & LSat & Vital & SelfEs & Opti \\
\hline WB & 1.00 & & & & & & & & & & & & & & \\
\hline Auto & 0.48 & 1.00 & & & & & & & & & & & & & \\
\hline Comp & 0.63 & 0.35 & 1.00 & & & & & & & & & & & & \\
\hline Engag & 0.62 & 0.22 & 0.43 & 1.00 & & & & & & & & & & & \\
\hline Purp & 0.61 & 0.27 & 0.43 & 0.37 & 1.00 & & & & & & & & & & \\
\hline Supp & 0.64 & 0.24 & 0.32 & 0.35 & 0.36 & 1.00 & & & & & & & & & \\
\hline Belon & 0.52 & 0.25 & 0.29 & 0.25 & 0.41 & 0.37 & 1.00 & & & & & & & & \\
\hline Resil & 0.42 & 0.22 & 0.29 & 0.27 & 0.21 & 0.26 & 0.19 & 1.00 & & & & & & & \\
\hline PA & 0.81 & 0.32 & 0.39 & 0.42 & 0.38 & 0.48 & 0.33 & 0.32 & 1.00 & & & & & & \\
\hline NA & -0.72 & -0.27 & -0.33 & -0.39 & -0.29 & -0.42 & -0.26 & -0.34 & -0.53 & 1.00 & & & & & \\
\hline Happ & 0.70 & 0.27 & 0.34 & 0.34 & 0.35 & 0.44 & 0.33 & 0.27 & 0.77 & -0.44 & 1.00 & & & & \\
\hline LSat & 0.76 & 0.35 & 0.42 & 0.39 & 0.43 & 0.44 & 0.39 & 0.32 & 0.68 & -0.50 & 0.74 & 1.00 & & & \\
\hline Vital & 0.76 & 0.30 & 0.39 & 0.46 & 0.34 & 0.39 & 0.26 & 0.35 & 0.55 & -0.61 & 0.42 & 0.49 & 1.00 & & \\
\hline SelfEs & 0.56 & 0.26 & 0.33 & 0.26 & 0.33 & 0.32 & 0.24 & 0.28 & 0.40 & -0.35 & 0.32 & 0.38 & 0.39 & 1.00 & \\
\hline Opti & 0.50 & 0.25 & 0.32 & 0.27 & 0.31 & 0.27 & 0.23 & 0.24 & 0.40 & -0.33 & 0.35 & 0.42 & 0.39 & 0.47 & 1.00 \\
\hline
\end{tabular}

Note. WB: Wellbeing Score; Auto: Autonomy; Comp: Competence: Engag: Engagement with Life; Purp: Purpose in Life; Supp: Supportive Relationships; Belon: Sense of Trust and Belonging; Resil: Resilience; PA: Positive Affect; NA: Negative Affect; Happ: Happiness; LSat: Life Satisfaction; Vital: Vitality; SelfEs: Self-Esteem; Opti: Optimism. All correlations $\mathrm{p}<.001$.

Table 6. Comparison of goodness of fit indices for models with increasing number of classes

\begin{tabular}{cccccccc}
\hline Class & AIC & BIC & Entropy & $\begin{array}{c}\text { VLMR- } \\
\text { LRT }\end{array}$ & P & LMR-LRT & P \\
\hline 2 & 264586 & 264641 & .80 & 30964.3 & $<.001$ & 30255.3 & $<.001$ \\
3 & 254382 & 254459 & .77 & 10211.6 & $<.001$ & 9977.8 & $<.001$ \\
4 & 250610 & 250708 & .71 & 3780.5 & $<.001$ & 3694.0 & $<.001$ \\
5 & 248754 & 248876 & .72 & 1863.6 & $<.001$ & 1820.9 & $<.001$ \\
6 & 247298 & 247441 & .73 & 1463.8 & $<.001$ & 1430.3 & $<.001$ \\
7 & 246390 & 246555 & .72 & 915.9 & $<.001$ & 895.0 & .001 \\
8 & 245829 & 246016 & .70 & 568.7 & .035 & 555.7 & .037 \\
9 & 245321 & 245530 & .73 & 512.7 & .185 & 504.4 & .189 \\
10 & 244961 & 245191 & .72 & 368.6 & .013 & 360.2 & .014 \\
11 & 244609 & 244861 & .72 & 360.2 & .056 & 351.9 & .059 \\
12 & 244296 & 244570 & .73 & 320.1 & .327 & 312.8 & .333 \\
\hline
\end{tabular}

Note. AIC: Akaike Information Criteria; BIC: Bayesian Information Criteria; VLMR LRT: Vuong-LoMendell-Rubin Likelihood Ratio Test; LMR LRT: Lo-Mendell-Rubin Likelihood Ratio Test.

As with the analysis of the individual indicators, model parsimony raises question of the need for additional classes that include only very small proportions of respondents. In the 7-class 
model, 2 classes reported proportions of $<5 \%$ (Class $2=2.4 \%$; Class $3=1.2 \%$ ) with an additional class (Class 5) reporting 5.2\%). In the 6-class model, 3 classes reported proportions $<5 \%$ (Class 2 $=4.7 \%$; Class $34.2 \%$; Class 4 1.5\%). In the 4- and 5-Class model, 1 class reported proportions of < 5\% (5-Class Model: Class 1 = 2.81.5\%; 4-Class model: Class $2=3.5 \%$ ); both of these classes reflected individuals who scored very low on all wellbeing domains. Consequently, we suggest that the 3class model is the more parsimonious model (See Figure 3) although we may understand that some researchers may find utility in deriving the very low wellbeing group in Class 4 although they accounted for only $3.5 \%$ of the sample. However, the more important point to emphasise here is that for most participants, class profiles of the higher-order wellbeing domains conforms with the analysis of the individual indicators; stable patterns were reported (See Figures 4a to $4 \mathrm{e}$ below). We would note that in the 6- and 7-class models, there was one small group of participants (6-Class Model: Class $3=4.2 \%$; 7 -Class Model: Class $2=2.4 \%$ ) who reported very low on SWB and PWB (second lowest in both models; <-1.5SD), and reported only low on SoWB (third lowest in both models; $\approx-0.5 \mathrm{SD}$ ), but this was the only indication of any form of 'complexity' reported.

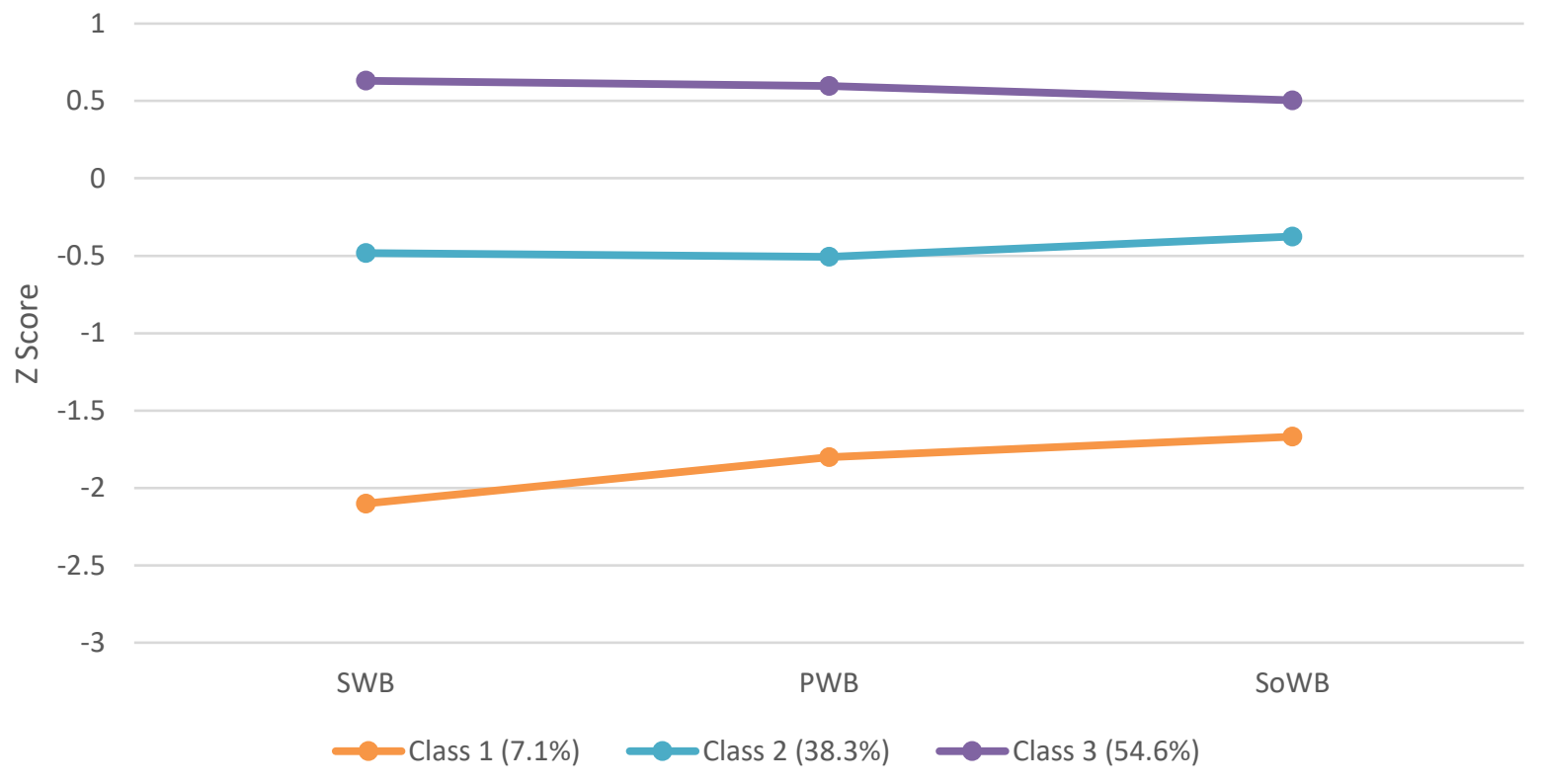

Figure 3. A 3-class profile analysis of the wellbeing higher-order factors

As with the analyses of the individual indicators, we examined the classification probabilities for most likely latent class membership, based on the posterior probabilities. On average the classification probabilities were high; $90.6 \%(\mathrm{SE}=0.2)$ for Class 1, 86.3\% (SE $=0.1)$ for Class 2, and $90.9 \%(\mathrm{SE}=0.1)$ for Class 3 (See Table 7 below). Where observations were not assigned their correct class, they were assigned to a class adjacent to their class. That is, $9.4 \%$ of the participants in Class 1 (lowest wellbeing class) and 9.1\% of the participants in Class 3 (highest wellbeing class) were not correctly assigned their respective class membership based on the posterior probabilities and were assigned into the adjacent Class 2 (the middle level of wellbeing). None of the observations from Class 1 (the lowest class) were assigned any probability for being in Class 3 (highest class), and none in Class 3 (the highest class) were assigned any probability for being in Class 1 (lowest class). In contrast, for those in the middle class, 2.6\% were assigned into Class 1 (the lowest class) and 11.2\% were assigned into Class 3 (the highest class). 


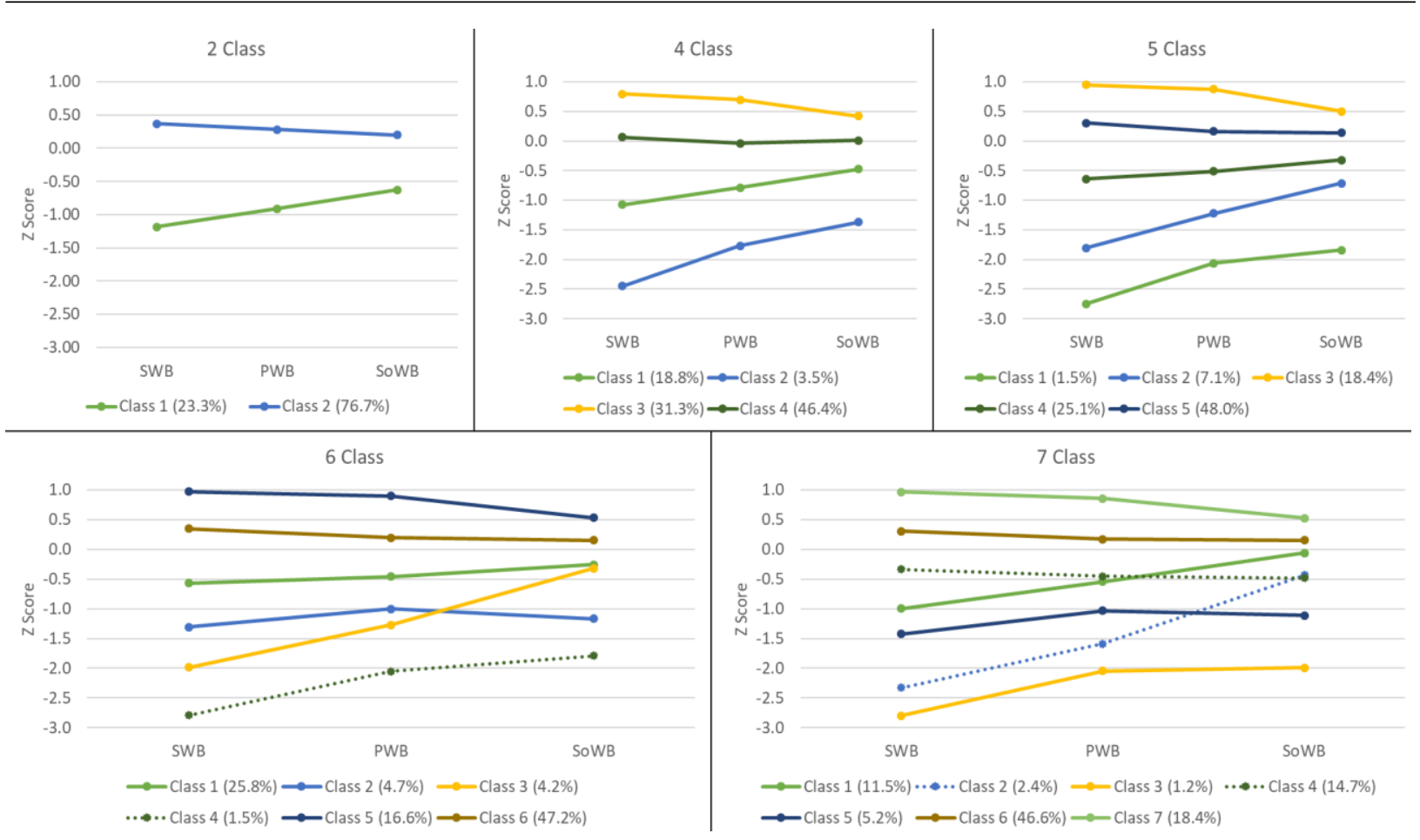

Figures 4a to 4e. Profile analysis plots of 2 thru 7-class of higher-order wellbeing factors

Table 7. Average class posterior probabilities of the higher-order wellbeing factors

\begin{tabular}{llll}
\hline \multirow{2}{*}{ Class Membership } & \multicolumn{4}{l}{ Class Membership based on Posterior Probabilities } \\
\cline { 2 - 4 } & \multicolumn{4}{l}{ 1 } & \multicolumn{3}{l}{3} \\
\cline { 2 - 4 } 1 & $\mathrm{M}(\mathrm{SE})$ & $\mathrm{M}(\mathrm{SE})$ & $\mathrm{M}(\mathrm{SE})$ \\
\cline { 2 - 4 } 2 & $90.2(.02)$ & $9.4(.01)$ & $0.0(.00)$ \\
3 & $2.6(.01)$ & $86.3(.01)$ & $11.2(.01)$ \\
\hline
\end{tabular}

As with the individual level factor scores, mean estimates on the wellbeing factor scores were consistent across all wellbeing factors, and socio-demographic differences were reported (Table 8 ), corresponding with the analyses of the mixture analyses of the classes derived from the

Table 8. Socio-Demographic characteristics of class membership

\begin{tabular}{|c|c|c|c|c|}
\hline & \multicolumn{3}{|l|}{ Classes } & \multirow[t]{3}{*}{ Test Statistic } \\
\hline & 1 (Low) & 2 (Average) & 3 (High) & \\
\hline & $\mathrm{M}(\mathrm{SE})$ & $\mathrm{M}(\mathrm{SE})$ & $\mathrm{M}(\mathrm{SE})$ & \\
\hline \multicolumn{5}{|l|}{ Wellbeing } \\
\hline SWB & $-2.17(.01)$ & $-.54(.00)$ & $.65(.00)$ & $\mathrm{F}(2)=43282.9 ; \mathrm{p}<.001$ \\
\hline PWB & $-1.85(.02)$ & $-.56(.01)$ & $.62(.00)$ & $F(2)=26626.9 ; p<.001$ \\
\hline SoWB & $-1.72(.02)$ & $-.42(.01)$ & $.52(.00)$ & $F(2)=15481.6 ; p<.001$ \\
\hline \multicolumn{5}{|l|}{ Socio-Demographic } \\
\hline Age & $50.06(.35)$ & $47.84(.15)$ & $47.30(.12)$ & $F(2)=29.07 ; p<.001$ \\
\hline Not Partnered, N(\%) & $1,577(55.1)$ & $7,736(49.3)$ & $10,561(43.8)$ & $\chi^{2}(2)=205.44 ; p<.001$ \\
\hline Female Sex, N(\%) & $1,676(58.4)$ & $8,925(56.6)$ & $12,762(52.7)$ & $\chi^{2}(2)=78.48 ; p<.001$ \\
\hline Tert. Educated, N(\%) & $602(20.9)$ & $3,804(24.2)$ & $7,199(29.8)$ & $\chi^{2}(2)=210.40 ; p<.001$ \\
\hline
\end{tabular}

Note. the $\mathrm{F}$ test is from a one-way ANOVA; $\chi^{2}$ is from a chi-square test. 
individual indicators. Generally, those who reported the higher levels of wellbeing, were of younger age, more likely to be partnered, and were a greater proportion who reported tertiary education. The correlations between variables were of moderate strength (Table 9; below).

Table 9. Correlations between higher-order wellbeing factors

\begin{tabular}{llll}
\hline & SWB & PWB & SOWB \\
\hline SWB & 1.00 & & \\
PWB & 0.66 & 1.00 & \\
SOWB & 0.56 & 0.53 & 1.00 \\
\hline
\end{tabular}

\subsection{Utility of latent class models}

Finally, we examined the utility of the latent classes, derived from both the lower and higherorder orders, to predict a range of health, social, employment and financial outcomes (Table 10). Overall, there appears to be a dose relationship with those classes reflecting higher wellbeing reporting better outcomes. This is particularly note worth for sleep quality. In addition, there are sizeable reductions in likelihood of reporting unemployment, both for self and partner, and lower likelihood of reporting difficulty in living on the household income. Notably, even one's partner unemployment status was related to personal wellbeing.

Table 10. Predictive utility of latent wellbeing classes on sleep quality, unemployment status and financial stress

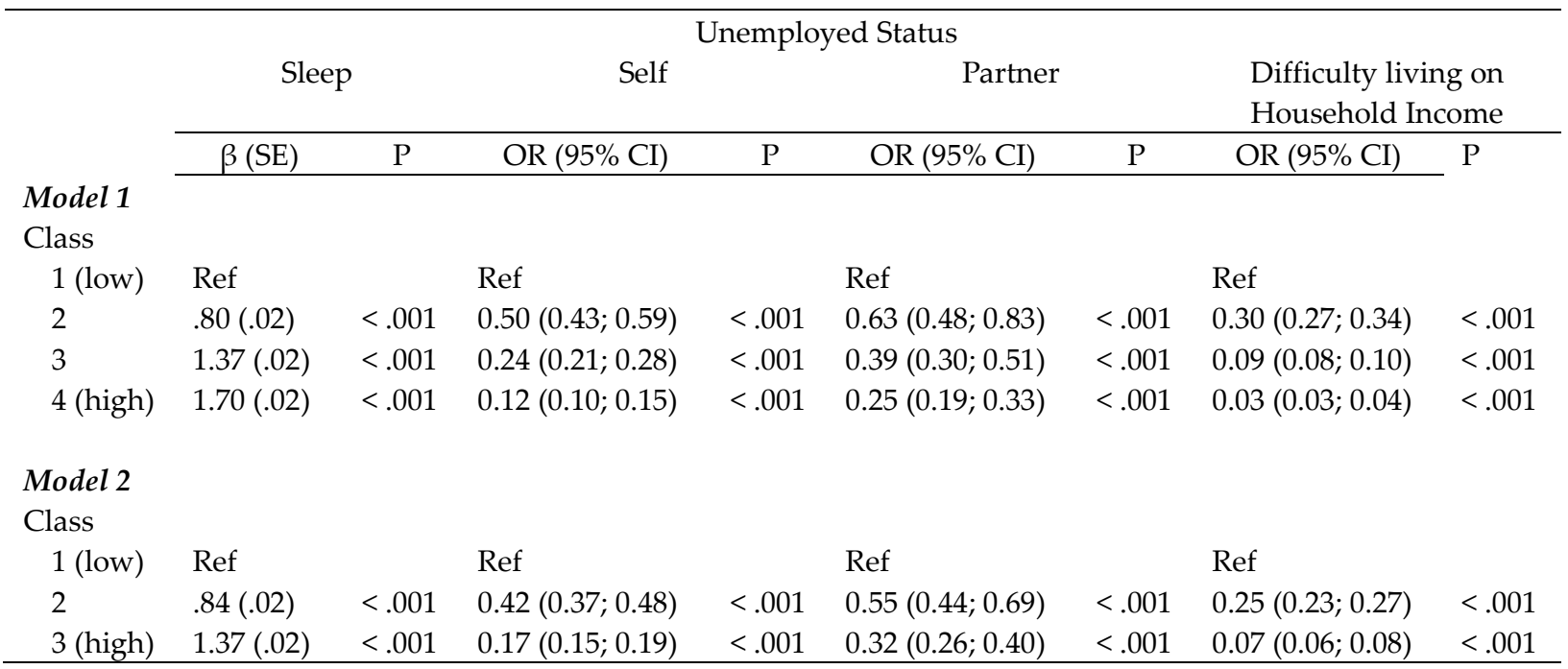

Note. Analyses adjusted for age, partner status, sex, education; all post-hoc comparisons between Classes reported $\mathrm{p}<.001$; beta reflect $\mathrm{SD}$ effect sizes

\section{Discussion}

Using data from a large European study comprising over 44,000 adults, there was no evidence that wellbeing complexity, specifically off-diagonal relationships where individuals score high on some indicators and low on others (Keyes et al., 2002), is a phenomena reported in the general population. Instead, profile analyses that increasingly extracted multiple profile classes consistently showed that the on-diagonal profile type was consistently reported. That is, between-person differences in the level on one wellbeing indicator was consistent across other wellbeing indicators. The findings are consistent with two smaller studies (Bhullar et al., 2014; Goodman et al., 2017) which focused on smaller numbers of wellbeing indicators. Replicating the 
analysis on the higher-order wellbeing factors (SWB, PWB, SoWB) confirmed this pattern at the higher level of the wellbeing hierarchy.

Comparison of wellbeing scores between classes confirmed that those in the higher wellbeing profile class reported higher on the overall wellbeing score, the individual wellbeing indicators, and the higher-order wellbeing actors. This does raise question regarding the importance of measuring multiple indicators of wellbeing since the on-diagonal relationship means that those who were high on one indicators were more likely to report higher (comparatively) on other wellbeing indicators. Even the analyses of the posterior probabilities identified that individuals not assigned their correct class, were still assigned into the next adjacent class. So clearly, even though there may be slight changes in the rank order between participants between multiple indicators, the magnitude of these changes does not appear to be substantial. Notably, the correlations between the individual indicators and overall wellbeing were strong to very high.

These findings are important for a number of reasons. There is clearly an appeal to a multidimensional model which taps into multiple wellbeing dimensions. In order to capture the full gamut of individual feeling and function, and intra-personal connection, there is an imperative to retaining multiple wellbeing indicators in scales of wellbeing. Univariate scales which promote summative overall wellbeing indices (Diener et al., 2010; Tennant et al., 2007) may ignore the subtlety of multiple measures captured by measures specifically designed to reflect multiple indicators of wellbeing (Marsh et al., 2020). Marsh's (2020) recent introduction of the WB-Pro scale, which was developed in part from the ESS wellbeing module used here, clearly showed that even several of the more commonly used uni-dimensional scales fail to capture the breadth of wellbeing domains and therefore provide only limited estimation of the general wellbeing factor. Wellbeing researchers need to consider whether their research questions are focused on specific lower-order wellbeing dimensions or higher-order general wellbeing factor. If the interest is in an overarching 'wellbeing' factor, then a broad and multiple indicator set of measures are needed, even though the evidence suggests that individuals are generally consistent across individual indicators, in comparison with their peers. The propensity for ondiagonal profile types to be reported in this paper and others (Bhullar et al., 2014), suggests that overall, individuals can be discriminated by their consistent likelihood of reporting the highest, average, or lowest overall wellbeing. One could conjecture we might well simply have defined these respondents by their score on an overall wellbeing score. But it is important to emphasise that an overall score in this context would reflect a higher-order factor derived from multiple indicators (Marsh et al., 2020), rather than scores derived from smaller unidimensional scales or scales that measure fewer domains (Diener et al., 2010; Tennant et al., 2007). This is important to emphasise.

There were a number of socio-demographic characteristics that discriminated between classes. Many of these were consistent with wellbeing findings from other studies. Large population studies frequently identify education engagement to be associated with better wellbeing and mental health outcomes (Araya et al., 2003) though a reciprocal relationship likely exists where those with better mental health and wellbeing are more likely to engage and complete education (Fergusson \& Woodward, 2002). Sex and age differences in wellbeing and mental health are well established (Burns et al., 2020; Charles et al., 2001; Ryff \& Singer, 2008; Shmotkin, 1990; Windsor et al., 2013). However, there remains a need to carefully interpret these differences; in terms of age, it has been argued that individuals prioritise different wellbeing dimensions as they age (Bowling, 2010; Burns, 2020; Charles et al., 2001). Future research should consider other individual level characteristics, including personality and individual differences, 
as well as other socio-demographic characteristics, which may discriminate between different wellbeing profiles. But if the evidence is that wellbeing provides are consistently on-diagonal types, then we would conjecture that there would be consistent findings between classes of wellbeing profiles for those who simply report high, moderate or low on an overall wellbeing factor score.

There are a number of limitations to the findings that warrant discussion. The profile analysis reflects group average estimates across multiple wellbeing indicators. We do not discount the possibility that some individuals who were categorised in the highest wellbeing class, may well have reported low or average on some indicators, and conversely for those who were categorised in the lowest wellbeing class (reported high or average on some indicators). Unlike traditional Latent Class Analyses where groups are homogenous, the estimation of class profiles from manifest variables with continuous distributions does mean that class point estimates have some degree of error. But still, the overall classification probabilities were very high and we can be confident that individuals' classification were based on their overall pattern of responses across multiple measures. This finding was consistent at both the lower and higher level of the factor structure.

We recognise that analysis of individual manifest indicators without considering global factors is an important issue to consider. Although not using standard measures of wellbeing, Morin et al. (2016) analysed patterns of serenity, harmony, involvement, anxiety and depression. Using a bi-factor approach, they undertook a profile analysis of individual factors and the ' $\mathrm{g}$ ' factor. Such approaches require further examination regarding their utility. For instance, previous reporting of the ESS wellbeing module suggests that a higher-order factor and not a Bifactor model best reflected the wellbeing structure in the European Social Survey (Burns, 2020). And Morin et al. (2016) identified classes that did not vary by more than 0.5SD across the individual wellbeing indicators; in contrast the classes derived from the current analyses differed by a far more substantive magnitude which may have more meaningful utility.

In contrast to these limitations, a strength of the study is that analyses focused on the individual or lower order wellbeing indicators, and the higher-order wellbeing domains, in the same study. The analyses of the lower level indicators is similar to Bhullar et al. (2014) profile analysis of the individual PWB indicators, and the analysis of the higher-order constructs is similar Keyes et al. (2002) which examined wellbeing complexity in terms of the higher-order SWB and PWB factors. Importantly, the study utilises data from a study that is not specifically a health study and responses are not likely to be adversely effected by self-selection into a wellbeing study. Further, the samples for each nation in the ESS were obtained using a probability sampling method, and the samples are representative of all persons aged 15 and over. Population weights are provided, but as 'population' estimates themselves are not an outcome of focus, weighting was not considered for the current paper. Finally, by utilising a more sophisticated data driven method to derive class profiles, the findings from this study failed to identify the off-diagonal relationships, whereby individuals reported mixed levels of SWB and PWB, previously reported by Keyes et al. (2002). Instead, the on-diagonal relationships reported conform with Bhullar et al. (2014) analyses of the Ryff PWB scales (Ryff \& Keyes, 1995) and the Goodman et al. (2017) analysis of the individual PERMA scales and SWB.

In conclusion, we have provided strong evidence that profiles of wellbeing can be derived using a sophisticated data analysis technique. However, there was no evidence for the experience of complexity in wellbeing experience. Instead, on-diagonal relationships were consistently reported and indicate stability in the rank order of between-person differences across multiple 
wellbeing measures. Continued research is needed to further extend the current findings and examine the concordance between multiple wellbeing and mental health indicators.

\section{Conflict of interest statement}

The authors declared no potential conflicts of interest with respect to the research, authorship, and/or publication of this article.

\section{Data Availability Statement}

Data is available from: https://www.europeansocialsurvey.org/.

\section{Authors}

Richard Burns

Australian National University, Australia

richard.burns@anu.edu.au

Dimity Crisp

University of Canberra, Australia

\section{Authors' Contributions}

$\mathrm{RB}$ conceived the research question, undertook the main analysis and drafted an initial draft of the manuscript. Both RB and DC made substantial contributions to the final version of the manuscript for publication.

\section{Publishing Timeline}

Received 11 February 2021

Revised version received 15 August 2021

Accepted 18 August 2021

Published 30 September 2021

\section{References}

Altman, D. G. (1991). Categorising continuous variables. British Journal of Cancer, 64(5), 975-975. https://doi.org/10.1038/bjc.1991.441

Araya, R., Lewis, G., Rojas, G., \& Fritsch, R. (2003). Education and income: Which is more important for mental health? Journal of Epidemiology and Community Health, 57(7), 501-505. https://doi.org/10.1136/jech.57.7.501

Bennette, C., \& Vickers, A. (2012). Against quantiles: categorization of continuous variables in epidemiologic research, and its discontents. BMC medical research methodology, 12, 21-21. https://doi.org/10.1186/1471-2288-12-21

Benyamini, Y., Idler, E. L., Leventhal, H., \& Leventhal, E. A. (2000). Positive affect and function as influences on self-assessments of health: Expanding our view beyond illness and disability. Journals of Gerontology Series B-Psychological Sciences and Social Sciences, 55(2), 107-116. https://doi.org/10.1093/geronb/55.2.p107

Bhullar, N., Hine, D. W., \& Phillips, W. J. (2014). Profiles of psychological well-being in a sample of Australian university students. International Journal of Psychology, 49(4), 288-294. https://doi.org/10.1002/ijop.12022

Boehm, J. K., \& Kubzansky, L. D. (2012). The heart's content: The association between positive psychological well-being and cardiovascular health. Psychological Bulletin, 138(4), 655-691. https://doi.org/10.1037/a0027448

Bousman, C. A., McKetin, R., Burns, R., Woods, S. P., Morgan, E. E., Atkinson, J. H., Everall, I. P., Grant, I., \& Group., t. T. M. A. R. C. (2015). Typologies of positive psychotic symptoms in 
methamphetamine dependence. The American Journal on Addictions, 24(2), 94-97. https://doi.org/10.1111/ajad.12160

Bowling, A. (2010). Do older and younger people differ in their reported well-being? A national survey of adults in Britain. Family Practice, 28(2), 145-155. https://doi.org/10.1093/fampra/cmq082

Brose, A., de Roover, K., Ceulemans, E., \& Kuppens, P. (2015). Older adults' affective experiences across 100 days are less variable and less complex than younger adults'. Psychology and Aging, 30(1), 194208. https://doi.org/10.1037/a0038690

Burns, R. A. (2020). Age-related differences in the factor structure of multiple wellbeing indicators in a large multinational European survey. Journal of Happiness Studies, 21(1), 37-52. https://doi.org/10.1007/s10902-019-00077-y

Burns, R. A., Butterworth, P., \& Crisp, D. A. (2020). Age, sex and period estimates of Australia's mental health over the last 17 years. Australian \& New Zealand Journal of Psychiatry, 54(6), 602-608. https://doi.org/10.1177/0004867419888289

Burns, R. A., \& Machin, M. A. (2009). Investigating the structural validity of Ryff's Psychological WellBeing Scales across two samples. Social Indicators Research, 93(2), 359-375. https://doi.org/10.1007/s11205-008-9329-1

Charles, S. T., Reynolds, C. A., \& Gatz, M. (2001). Age-related differences and change in positive and negative affect over 23 years. Journal of Personality \& Social Psychology, 80(1), 136-151.

Chen, F. F., Jing, Y., Hayes, A., \& Lee, J. M. (2013). Two concepts or two approaches? A bifactor analysis of psychological and subjective well-being. Journal of Happiness Studies, 14(3), 1033-1068.

Compton, W. C., Smith, M. L., Cornish, K. A., \& Qualls, D. L. (1996). Factor structure of mental health measures. Journal of Personality and Social Psychology, 71(2), 406-413. https://doi.org/10.1037//00223514.71.2.406

de Bruin, G. P., \& du Plessis, G. A. (2015). Bifactor analysis of the mental health continuum-short form (MHC-SF). Psychological Reports, 116(2), 438-446. https://doi.org/10.2466/03.02.PR0.116k20w6

Deci, E. L., \& Ryan, R. M. (2000). The "what" and "why" of goal pursuits: Human needs and the selfdetermination of behavior. Psychological Inquiry, 11(4), 227-268. https://doi.org/10.1207/s15327965pli1104_01

Diener, E., Wirtz, D., Tov, W., Kim-Prieto, C., Choi, D.-w., Oishi, S., \& Biswas-Diener, R. (2010). New well-being measures: Short scales to assess flourishing and positive and negative feelings. Social Indicators Research, 97(2), 143-156.

Disabato, D. J., Goodman, F. R., Kashdan, T. B., Short, J. L., \& Jarden, A. (2016). Different types of wellbeing? A cross-cultural examination of hedonic and eudaimonic well-being. Psychological Assessment, 28(5), 471-482. https://doi.org/10.1037/pas0000209

European Social Survey. (2006). Data file edition 3.6. NSD - Norwegian Centre for Research Data, Norway - Data Archive and distributor of ESS data for ESS ERIC.

Fergusson, D. M., \& Woodward, L. J. (2002). Mental health, educational, and social role outcomes of adolescents with depression. Archives of General Psychiatry, 59(3), 225-231. https://doi.org/10.1001/archpsyc.59.3.225

Gallagher, M. W., Lopez, S. J., \& Preacher, K. J. (2009). The hierarchical structure of well-being. Journal of Personality, 77(4), 1025-1050. https://doi.org/10.1111/j.1467-6494.2009.00573.x

Gatt, J. M., Burton, K. L. O., Schofield, P. R., Bryant, R. A., \& Williams, L. M. (2014). The heritability of mental health and wellbeing defined using COMPAS-W, a new composite measure of wellbeing. Psychiatry Research, 219(1), 204-213. https://doi.org/10.1016/j.psychres.2014.04.033

Goodman, F. R., Disabato, D. J., Kashdan, T. B., \& Kauffman, S. B. (2017). Measuring well-being: A comparison of subjective well-being and PERMA. The Journal of Positive Psychology, 13(4), 321-332. https://doi.org/10.1080/17439760.2017.1388434

Greenland, S. (1995). Avoiding power loss associated with categorization and ordinal scores in doseresponse and trend analysis. Epidemiology, 6(4), 450-454. https://doi.org/10.1097/00001648-19950700000025

Grühn, D., Lumley, M. A., Diehl, M., \& Labouvie-Vief, G. (2013). Time-based indicators of emotional complexity: Interrelations and correlates. Emotion, 13(2), 226-237. https://doi.org/10.1037/a0030363 
Hay, E. L., \& Diehl, M. (2011). Emotion complexity and emotion regulation across adulthood. European Journal of Ageing, 8(3), 157-168. https://doi.org/10.1007/s10433-011-0191-7

Hershfield, H. E., Scheibe, S., Sims, T. L., \& Carstensen, L. L. (2013). When feeling bad can be good: Mixed Emotions benefit physical health across adulthood. Social Psychological and Personality Science, 4(1), 54-61. https://doi.org/10.1177/1948550612444616

Hervás, G., \& Vázquez, C. (2013). Construction and validation of a measure of integrative well-being in seven languages: The Pemberton Happiness Index. Health and Quality of Life Outcomes, 11, 66-66. https://doi.org/10.1186/1477-7525-11-66

Hides, L., Quinn, C., Stoyanov, S., Cockshaw, W., Mitchell, T., \& Kavanagh, D. J. (2016). Is the mental wellbeing of young Australians best represented by a single, multidimensional or bifactor model? Psychiatry Research, 241, 1-7. https://doi.org/10.1016/j.psychres.2016.04.077

Hu, M. C., Muthen, B., Schaffran, C., Griesler, P. C., \& Kandel, D. B. (2008). Developmental trajectories of criteria of nicotine dependence in adolescence. Drug and Alcohol Dependence, 98(1-2), 94-104. https://doi.org/10.1016/j.drugalcdep.2008.04.017

Huppert, F. A., Marks, N., Clark, A., Siegrist, J., Stutzer, A., Vittersø, J., \& Wahrendorf, M. (2009). Measuring well-being across Europe: Description of the ESS well-being module and preliminary findings. Social Indicators Research, 91(3), 301-315. https://doi.org/10.1007/s11205-008-9346-0

Huppert, F. A., \& So, T. T. C. (2013). Flourishing Across Europe: Application of a New Conceptual Framework for Defining Well-Being. Social Indicators Research, 110(3), 837-861. https://doi.org/10.1007/s11205-011-9966-7

Jovanović, V. (2015). A bifactor model of subjective well-being: A re-examination of the structure of subjective well-being. Personality and Individual Differences, 87, 45-49. https://doi.org/http://dx.doi.org/10.1016/j.paid.2015.07.026

Jowell, R. (2007). Measuring attitudes cross-nationally : lessons from the European Social Survey. SAGE.

Kashdan, T. B., Barrett, L. F., \& McKnight, P. E. (2015). Unpacking emotion differentiation: Transforming unpleasant experience by perceiving distinctions in negativity. Current Directions in Psychological Science, 24(1), 10-16. https://doi.org/10.1177/0963721414550708

Keyes, C. L., Shmotkin, D., \& Ryff, C. D. (2002). Optimizing well-being: The empirical encounter of two traditions. Journal of Personality \& Social Psychology, 82(6), 1007-1022.

Keyes, C. L. M. (1998). Social Well-Being. Social Psychology Quarterly, 61(2). https://doi.org/10.2307/2787065

Kim, K., Lehning, A. J., \& Sacco, P. (2016). Assessing the factor structure of well-being in older adults: findings from the National Health and Aging Trends Study. Aging \& Mental Health, 20(8), 814-822. https://doi.org/10.1080/13607863.2015.1037245

Linley, P. A., Maltby, J., Wood, A. M., Osborne, G., \& Hurling, R. (2009). Measuring happiness: The higher order factor structure of subjective and psychological well-being measures. Personality and Individual Differences, 47(8), 878-884. https://doi.org/10.1016/j.paid.2009.07.010

Lo, Y. T., Mendell, N. R., \& Rubin, D. B. (2001). Testing the number of components in a normal mixture. Biometrika, 88(3), 767-778. https://doi.org/10.1093/biomet/88.3.767

Longo, Y., Jovanovic, V., Sampaio de Carvalho, J., \& Karas, D. (2020). The general factor of well-being: Multinational evidence using bifactor ESEM on the Mental Health Continumm-Short Form. Assessment, 27(3), 596-606. https://doi.org/10.1177/1073191117748394

Lu, M. C., Korst, L. M., Fridman, M., Muthengi, E., \& Gregory, K. D. (2009). Identifying women most likely to benefit from prevention strategies for postpartum hemorrhage. Journal of Perinatology, 29(6), 422-427. https://doi.org/10.1038/jp.2009.2

Lubke, G. H., \& Miller, P. J. (2015). Does nature have joints worth carving? A discussion of taxometrics, model-based clustering and latent variable mixture modeling. Psychological Medicine, 45(4), 705-715. https://doi.org/10.1017/S003329171400169x

Marsh, H. W., Huppert, F. A., Donald, J. N., Horwood, M. S., \& Sahdra, B. K. (2020). The well-being profile (WB-Pro): Creating a theoretically based multidimensional measure of well-being to advance theory, research, policy, and practice. Psychological Assessment, 32(3), 294-313.

https://doi.org/10.1037/pas0000787 
McKetin, R., Dawe, S., Burns, R. A., Hides, L., Kavanagh, D. J., Teesson, M., McD. Young, R., Voce, A., \& Saunders, J. B. (2016). The profile of psychiatric symptoms exacerbated by methamphetamine use. Drug and Alcohol Dependence, 161, 104-109. https://doi.org/10.1016/j.drugalcdep.2016.01.018

Morin, A. J. S., Boudrias, J.-S., Marsh, H. W., Madore, I., \& Desrumaux, P. (2016). Further reflections on disentangling shape and level effects in person-centered analyses: An illustration exploring the dimensionality of psychological health. Structural Equation Modeling: A Multidisciplinary Journal, 23(3), 438-454. https://doi.org/10.1080/10705511.2015.1116077

Muthen, B. (2006). Should substance use disorders be considered as categorical or dimensional? Addiction, 101 Suppl 1, 6-16. https://doi.org/10.1111/j.1360-0443.2006.01583.x

Muthen, B. (2008). Latent variable hybrids - Overview of old and new models. In G. R. Hancock \& K. M. Samuelsen (Eds.), Advances in Latent Variable Mixture Models (pp. 1-24).

Muthén, B. (2004). Latent variable analysis: Growth mixture modeling and related techniques for longitudinal data. In D. Kaplan (Ed.), Handbook of quantitative methodology for the social sciences. SAGE.

Nylund-Gibson, K., \& Choi, A. Y. (in press). Ten frequently asked questions about latent class analysis. Translational Issues in Psychological Science.

Nylund, K. L., Asparouhov, T., \& Muthen, B. O. (2008). Deciding on the number of classes in latent class analysis and growth mixture modeling: A Monte Carlo simulation study. Structural Equation Modeling-a Multidisciplinary Journal, 15(1), 182-182. https://doi.org/10.1080/10705510701793320

O'Toole, M. S., Renna, M. E., Elkjær, E., Mikkelsen, M. B., \& Mennin, D. S. (2020). A systematic review and meta-analysis of the association between complexity of emotion experience and behavioral adaptation. Emotion Review, 12(1), 23-38. https://doi.org/10.1177/1754073919876019

Ong, A. D., \& Bergeman, C. S. (2004). The complexity of emotions in later life. The Journals of Gerontology Series B: Psychological Sciences and Social Sciences, 59(3), 117-122. https://doi.org/10.1093/geronb/59.3.P117

Ryff, C. D. (1989). Happiness is everything, or is it? Explorations on the meaning of psychological wellbeing. Journal of Personality and Social Psychology, 57(6), 1069-1081.

Ryff, C. D., \& Keyes, C. L. M. (1995). The structure of psychological well-being revisited. Journal of Personality and Social Psychology, 69(4), 719-727. https://doi.org/10.1037//0022-3514.69.4.719

Ryff, C. D., \& Singer, B. H. (2008). Know thyself and become what you are: A eudaimonic approach to psychological well-being. Journal of Happiness Studies, 9(1), 13-39. https://doi.org/10.1007/s10902-0069019-0

Savoie, A., Boudrias, J.-S., \& Gilbert, M.-H. (2010). Surenchère de la non-santé psychologique au travail. Le Journal des psychologues, 283(10), 31-34. https://doi.org/10.3917/jdp.283.0031

Seligman, M. E. P. (2011). Flourish : a visionary new understanding of happiness and well-being (1st Free Press hardcover ed.). Free Press.

Shmotkin, D. (1990). Subjective well-being as a function of age and gender: A multivariate look for differentiated trends. Social Indicators Research, 23(3), 201-230. https://doi.org/10.1007/BF00293643

Tennant, R., Hiller, L., Fishwick, R., Platt, S., Joseph, S., Weich, S., Parkinson, J., Secker, J., \& StewartBrown, S. (2007). The Warwick-Edinburgh Mental Well-being Scale (WEMWBS): Development and UK validation. Health and Quality of Life Outcomes, 5(1), 63. https://doi.org/10.1186/1477-7525-5-63

Uher, R., Muthen, B., Souery, D., Mors, O., Jaracz, J., Placentino, A., Petrovic, A., Zobel, A., Henigsberg, N., Rietschel, M., Aitchison, K. J., Farmer, A., \& McGuffin, P. (2010). Trajectories of change in depression severity during treatment with antidepressants. Psychological Medicine, 40(8), 1367-1377. https://doi.org/10.1017/S0033291709991528

Van Horn, J. E., Taris, T. W., Schaufeli, W. B., \& Schreurs, P. J. G. (2004). The structure of occupational well-being: A study among Dutch teachers. Journal of Occupational and Organizational Psychology, 77(3), 365-375. https://doi.org/10.1348/0963179041752718

van Walraven, C., \& Hart, R. G. (2008). Leave 'em alone - why continuous variables should be analyzed as such. Neuroepidemiology, 30(3), 138-139. https://doi.org/10.1159/000126908

Veenhoven, R. (1995). The cross-national pattern of happiness: Test of predictions implied in three theories of happiness. Social Indicators Research, 34(1), 33-68. https://doi.org/10.1007/BF01078967 
Windsor, T. D., Burns, R. A., \& Byles, J. E. (2013). Age, physical functioning, and affect in midlife and older adulthood. Journals of Gerontology Series B-Psychological Sciences and Social Sciences, 68(3), 395399. https://doi.org/10.1093/geronb/gbs088 